\title{
EVALUATING THE EFFECTIVENESS OF TEACHING METHODS USED FOR GCE AND SSC LEVELS
}

\author{
Muhammad Safdar Bhatti ${ }^{1 *}$, Rafia Mukhtar ${ }^{2}$, Shahla Bajwa ${ }^{3}$ \\ ${ }^{1}$ TEFL Coordinator, AIOU Bahawalpur, Pakistan, safdarbhatti2001@gmail.com \\ 2Director, SAQE, Bahawalpur, Pakistan, saqe1994@gmail.com \\ ${ }^{3}$ Instructor, SAQE, Bahawalpur, Pakistan, shahla.bajwa@hotmail.com \\ ${ }^{*}$ Corresponding Author
}

\begin{abstract}
The present research focuses on comparative study of the Secondary School Certificate (SSC) and the General Certificate of Education-Ordinary level (GCE-O level) English language course to trace out the problems and shortcomings of the curriculum objectives and teaching methods. The objectives of the study were to analyze the objectives of teaching English of SSC and GCE O-level to critically review the teaching methodologies of both the courses. The population of the study comprised of all the teachers and the students of SSC and GCE-O level of Bahawalpur region. The sample included the teachers and the students of $10^{\text {th }}$ class \& GCE (O level) only. A test was designed about Essay writing, Story writing \& Comprehension skills. An observation sheet was also designed with the four-points rating scale for the teachers and the students as well. The researchers concluded that the teachers teaching O-level students followed studentcentered and language-centered approaches which catered the interests and needs of the students. They ensured participation of the students in the learning process whereas in SSC, the teachers used to follow teacher-centered approach. The Grammar Translation Methods (GTM) was used to teach English language at SSC level students while the Direct and Activity-based methods were used to teach O-level students. The main recommendations were that the SSC curriculum needs to be revised and modified according to the students' needs. The English language teachers at SSC level may also motivate the students to use authentic materials, pair work and group work in the classroom. The public schools may be equipped with libraries, language labs and audio-visual materials such as tape recorder, video-player, overhead projector, multi-media and such facilities may be properly used for improving the teaching learning process.
\end{abstract}

Keywords: Evaluating, effectiveness, teaching methods, motivate, learning process

\section{INTRODUCTION}

Educational process is directed through formal, informal and non-formal ways. For this purpose, there is a need of interaction among the learner, educator and the study material. Usually, educational system at the primary level follows the medium of instructions in mother tongue. In Pakistan, the students have to study 
English as a compulsory subject from K.G to graduation level. A Pakistani learner is interested in learning English language due to following reasons:

1- To search out advanced studies outside Pakistan.

2- To contain excellent job opportunities in a foreign country.

3- For missionary, armed forces and social purposes.

4- For commerce and trade.

5- For learning and educational purposes.

English language was first brought to Britain in the fifth century A.D. by settlers from the European mainland. Arabic, Persian and Sanskrit were the medium of instruction before the advent of British in the sub-continent. Lord Macaulay's reform in favor of English language as a medium of instruction in 1835 brought an end to the Oriental languages. The need for English became greater in 1854 when the eligibility to government service was restricted to those who had English education (Mansoor, 1993).

The table below unveils the origin of language:

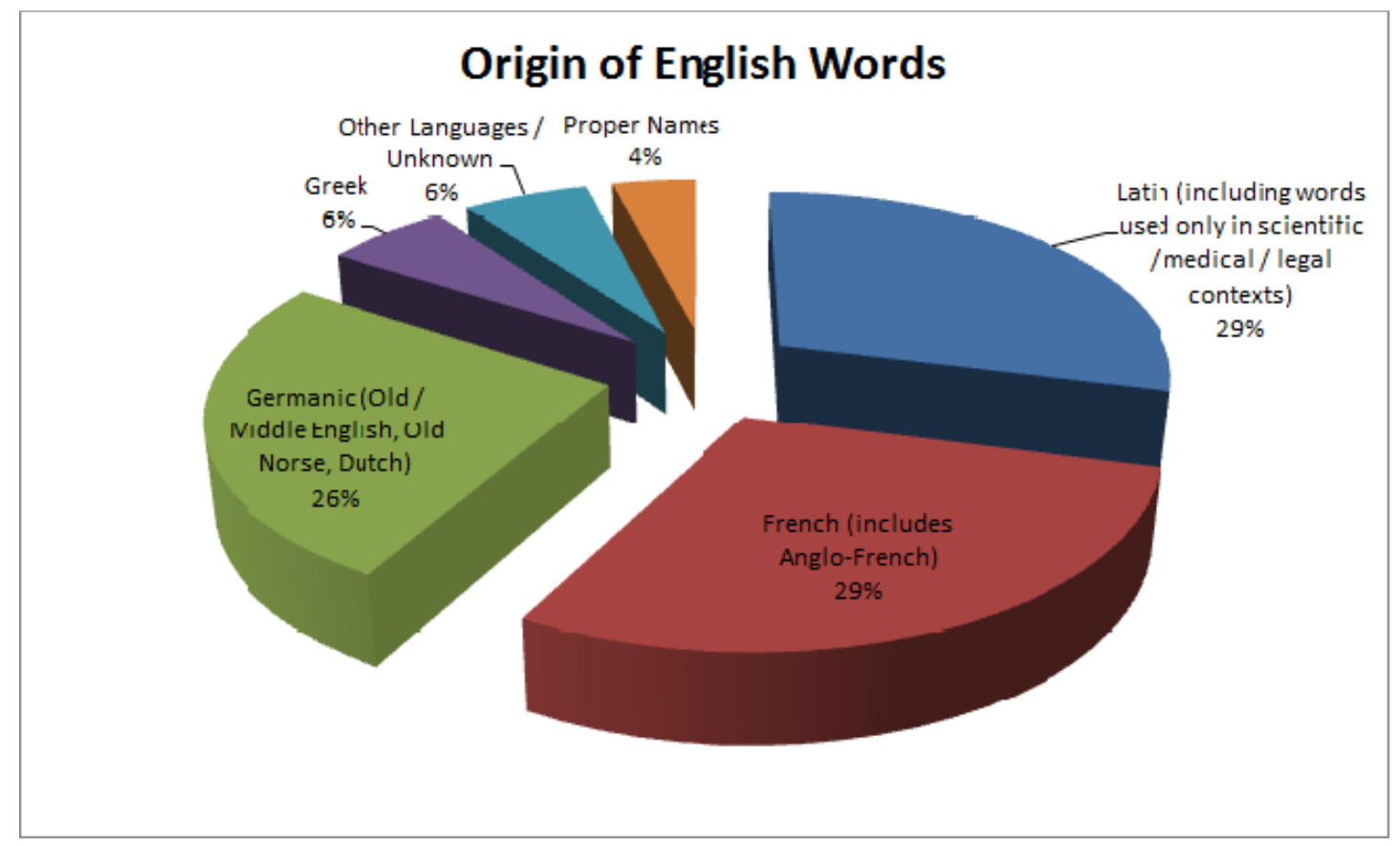

Fig No. 1.1

Naeemullah (2007); Kiyani (2002) conducted a research on comparative analysis of SSC and GCE-O level programs with special reference to science education. The major objectives of the study were to conduct a comparative analysis of policy objective, scheme of studies, curriculum objectives, contents, teaching methods and examination system of Pakistani secondary GCE-O level program with special reference to Pakistan. The researchers explored through their studies that GCE-A level curriculum development process, curriculum objectives, curriculum contents, teaching methods and examination system were better as compared to Higher Secondary School Certificate (HSSC) in Pakistan. The equipment and the teacher's performance are better as compared to SSC level system.

Waheed (2005) conducted A Comparative Study of English Language writing courses meant for teaching writing skills at SSC Level and O levels programs. The findings of the study indicated that O Level students are good at English in terms of writing skills whereas the courses at SSC Level encourage cramming which is hazardous in the development of writing skills. There is no room for Functional courses that promote understanding and concept based learning at SSC Level programs.

According to Umbreen (2008), the teachers working in O level system were highly qualified and well experienced but untrained. They prepared lesson plan before presentation of lecture in the classroom to the students and used to encourage questioning in the class in order to build more confidence and better understanding of students. Majority of respondents in the study revealed that the environment of $O$ and $A$ level institutions was suitable for teaching and learning. They were satisfied with the facilities provided by the 
institutions. It was found that in $\mathrm{O}$ and $\mathrm{A}$ level systems, syllabus was revised according to global trends and the contents were according to the mental level of the students. It was also observed that the books in $\mathrm{O}$ and A level contain sufficient number of graphs, figures and pictures to explain the concepts. The respondents agreed that policy objectives of $\mathrm{O}$ and $\mathrm{A}$ level curriculum were well formulated. Most of parents and teachers agreed that $\mathrm{O}$ and $\mathrm{A}$ level education system was knowledge based that promotes intellectual development of the students. It was also found that $O$ and $A$ level education system promote creativity in the students.

The fundamental principle of the Education Act 1944, which inspired the education system, was the idea of 'Secondary Education for All' (Graves, 1988). In 1988, a major change took place in the British education system and the prevalent nomenclature of (GCSE) was replaced by the General Certificate of Education (GCE O-level) (Whitaker, 1999).

Since 1951, the GCE examinations are being conducted in the United Kingdom at two main levels: Ordinary Level (O-level) and the Advanced Level (A-level). In Pakistan these programs are being offered since 1959. In the United Kingdom the GCE O-level examinations are no more being held at all. However, international students outside the United Kingdom are still following the same scheme of studies for "O" and "A" level exams that are being conducted by the following examination boards:

a) University of Cambridge Local Examination Syndicate (UCLES).

b) Edexcel International London Examinations (EILE)

c) University of Oxford Delegacy of Local Examinations (UODLE)

d) The British Council, 2002)

In Pakistan there are many institutions which offer GCE O-level to the students but the number of recognized institutions in the British Council is 180. The GCE O-level is a world recognized program. Though the SSC and GGE O-level are running parallel yet it is commonly assumed that they are creating discrimination between the persons qualifying from these two systems. The GCE O-level system of education is for the elite class while the SSC level system of education is providing education to the common people. No significant research work appears to have been carried out to make the comparative analysis of the GCE O-level and the SSC education in Pakistan, with a special reference to English language. Therefore the current study has been designed to probe the issue at large.

\subsection{Statement of the Problem}

The researchers have observed that the GCE (O-Level) students are capable enough to produce good English rather than the students of SSC (Secondary School Certificate). The researchers aim to draw the comparison of teaching methodologies used for teaching English at GCE (O-Level) and SSC level. This research will be helpful for the teachers to find out the problems and suitable remedies to enhance the English language standard particularly at SSC level.

\subsection{Research Questions}

The problems which will be observed in this study are:

- How for are the objectives of English language learning appropriate at GCE (O-Level) and SSC?

- Why do the students of GCE (O-Level) produce better results in English than SSC?

- What are the teaching methodologies which can help the students to enhance the English Language learning?

\subsection{Hypothesis of the Study}

Whether teaching methodologies used for GCE (O-Level) are better than SSC (Secondary School Certificate).

\subsection{Objectives of the Study}

The major objectives of the study were:

1. To analyze the objectives of teaching English of SSC and GCE O-level.

2. To critically review the teaching methodologies used for both the programs.

3. To compare the academic achievements of both the programs. 


\subsection{Significance of the Study}

The findings of the study would provide guidelines to the curriculum planners, managers and experts in redefining the objectives of the secondary school English language curriculum. It may facilitate the course developers to design the English language course according to the international standards. The educational planners and administrators may consider reallocation of funds for training of the English language teachers. Furthermore it would help the English language teachers particularly to teach English as a foreign language in an effective way.

\subsection{Population and Sampling}

Students of $10^{\text {th }}$ class of Alpina School (Girls) Bahawalpur and the Students of GCE (O-Level) of The City School, Bahawalpur were the population of the present study. For the purpose of research, a sample of 60 students from SSC system of education and 60 students from GCE (O-Level) were selected randomly.

\subsection{Delimitation of the Study}

The researchers confined only to teaching methodologies used for teaching English in both systems. Moreover this research is based only on the teachers and students of Alpina School (Girls) Bahawalpur and The City School, Bahawalpur.

\section{LITERATURE REWIEW}

\subsection{Language and its Learning}

The gift of gab is a special blessing of the Creator to mankind. This quality distinguishes the human beings from animals. According to Chomsky (1988), the learning of a language is an exclusive faculty of human beings and does not exist in any other species. Although animals like monkeys, dolphins and some others can communicate with one another through language yet they cannot use language as creatively as the human beings can do. They can communicate only in a fixed way by using certain specific signals.

According to Nunand (2003), language is the best taught when it is used to communicate messages, not when it is explicitly taught for conscious learning. Language acquisition can only take place when a message, which is being transmitted, is properly understood, and the focus is on what is being said rather than on the form of the message.

According to Rehman (2003), language is a cultural symbol that preserves and transmits culture to the coming generations and it is also a means of systematic communication by vocal symbols. "Language is a system of arbitrary, vocal symbols, which helps all people in a given culture to communicate". Language is a learned behavior. All normal children are born with the ability to make sounds but sounds take the shape of language and become meaningful only through constant hearing and repeating them. The sounds may be taught first in isolation but must instantly be inserted in words and phrases etc.

Culture and language are so closely inter-connected and inter-dependent that their independent survival is almost impossible. Nunand also points out that features of a language are not inherited in a biological sense. Any hereditary difference in the structure of a larynx, mouth and lips does not influence the action, which makes up a language. A child learns to speak like other people who are around him.

According to Moeen (1992), the child uses noise and loudness with a rudimentary system of information before he learns specific words, uses utterances for a period and develops intonation akin to the intonation of his parents. Development of his intonation may go for ahead of other elements and units of the language.

The components of language are as under:

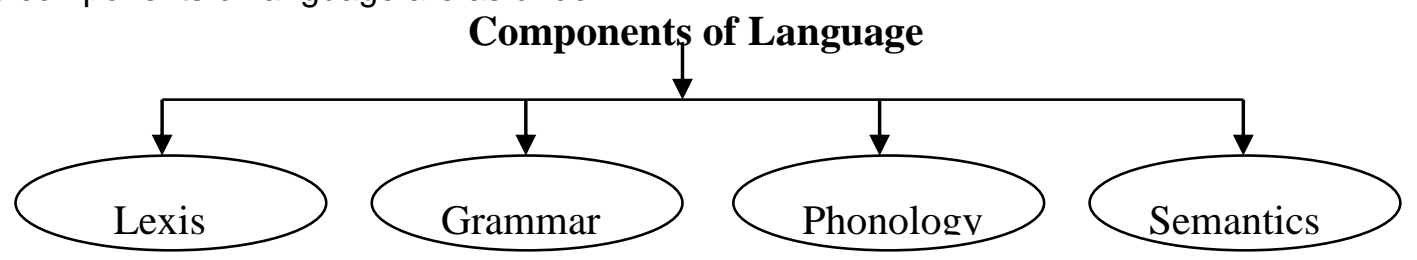

\section{(a) Lexis}

Lexis carries great significance in a language. It is just like the flesh of a living organism and it gives richness and extensiveness to a language. 


\section{(b) Grammar}

According to Michael (2005), Grammar gives structure and form to a language. It is just like a network of bones within the body of an organism. Combining together Lexis and Grammar, they give birth to a language and almost all the languages have the following systems:
a. Grammatical system
b. Phonological system
c. Lexical system

\section{(c) Phonology}

It is the system of sounds in a language. Any message conveyed by a language has to be first converted into words put together according to the grammatical rules and these words are then conveyed by sounds. It is a broader study of the major speech sounds and their organization in a particular language. Moreover, it deals with how English organizes elements of speech into an integrated system. Accuracy, fluency, and intonation are the main purposes of phonology. Intonation is concerned with the pitch of the voice, the musical feature of the voice (Michael, 2005).

\section{(d) Semantics}

Semantics is the study of meanings in a language. And a language in itself is very sensitive to the situation. So it is rather difficult to reach at the exact meanings of words in a sentence. The aim of semantics is, to explain and clarify the nature of meaning (Shams, 2003).

\subsection{Learning English as a Second Language}

According to French (2000), learning a second language is more important than learning a description of it. It involves imitating, practicing, memorizing, listening, interpreting, reading, writing and speaking. Further stated that pupil's learning of the new language and teaching of a language should be based on word groups. It is the phrase-pattern and sentence pattern that are of primary importance. According to him, there are three basic principles: Word order is the first principle, word's structure is the second principle and inflexions or changes or a difference in the form of words is the third principle.

\subsection{Four English Language Learning Skills}

Harris (1969) narrated, "Two linguistic activities, which are associated with both speech and writing, are encoding and a decoding processes. Speaking and writing themselves are the encoding processes whereby everyone communicates one's ideas, thoughts, or feelings in one or the other form. Listening and Reading are the parallel decoding processes by which everyone understands either spoken or a written message". According to Harris "language includes four skills, or complexes of skills: Listening, Speaking, Reading and Writing. It is perhaps in this order that everyone originally learns one's native language".

\section{METHODOLOGY}

\subsection{Research Method}

The researchers have chosen quantitative research methodology for this research. In quantitative research the causal comparative method has been used. The study is based on a comparative analysis of teaching methodologies used for GCE and SSC levels.

\subsection{Sample of the Study}

In this study, 30 students were selected randomly from Alpina School (Girls) Bahawalpur and the City School, Bahawalpur. Students were almost of the same age group which is 14-16 years.

\subsection{Place and Time of the Study}

This study was carried out in 3 months December 2016 to February 2017. A one collective test has been taken and the 60 observations have been taken in both of the systems i.e. GCE (O' level) and SSC (Matriculation) with the permission of head teacher and class teacher.

\subsection{Research Instruments}

In this quantitative study, the researchers had used:

- Questionnaire

- Language Classroom Observation Sheets for Teachers

- Language Skill Observation Sheets for Students 
Before the test the pilot testing had been done for checking its reliability and validity.

\subsection{Structure of Questionnaire}

A questionnaire was used for test which comprise of three questions. Question 1 was of descriptive writing, question 2 was of narrative writing and question 3 contains a comprehension passage. The test was of 30 marks. Each question carried equal marks. This test was chosen because other methods were not as convenient to apply.

\subsection{Structure of Language Classroom Observation Sheet for Teachers}

A close questionnaire has been used for the observations with the rating scale 4=Outstanding; $3=$ Good; $2=$ Fair and $1=$ Poor. As a close questionnaire is quicker to answer and easier to analyze than an open one where the respondent have to create their own answer. The questionnaire is based on the language classroom observation as preparation, language use, lesson presentation, classroom management, and classroom atmosphere, use of technology and use of teaching methodologies.

\subsection{Structure of Language Skill Observation Sheet for Students}

A close questionnaire has been used to observe the students' language skills with the rating scale 4=Outstanding; 3=Good; $2=$ Fair and 1=Poor. As a close questionnaire is quicker to answer and easier to analyze than an open one where the respondent have to create their own answer. The questionnaire is based on four language skills reading, writing, speaking and listening.

\subsection{Data Collection}

The students were given the questionnaires which were dully filled and completed in the presence of the researchers. So the data was collected in the same way from both schools. The data was arranged in the tabular form and percentage and frequencies were calculated.

\section{DATA ANALYSIS}

The questionnaire data was analyzed manually while the data of observation sheen had been analyzed and results were tabulated by statistical tools i.e. MS Excel, SPSS20.

\subsection{Questionnaire Result}

As the researchers had selected the causal comparative research and had designed a questionnaire which consisted of three questions: essay writing, story writing and a comprehension passage. Each question was of 10 marks. Total weightage of the questionnaire was 30. The number of students was 30 from each school who were selected randomly for the current study from Alpina School (Girls), Bahawalpur and the City School, Bahawalpur. The students had completed this questionnaire under the favorable conditions and the statistical evaluations of the results are:

\begin{tabular}{|c|c|}
\hline GCE (O' Levels) & SSC (Secondary School Certificate) \\
\hline
\end{tabular}


IJAEDU- International E-Journal of Advances in Education, Vol. III, Issue 9, December 2017

\begin{tabular}{|c|c|c|c|}
\hline$\sum x_{1}$ & $\sum x_{1}^{2}$ & $\sum x_{2}$ & $\sum x_{2}^{2}$ \\
\hline 719 & 17361 & 531 & 9487 \\
\hline$=\underline{\sum x_{1}}$ & & $=\underline{\sum x_{2}}$ & \\
\hline$=\bar{n}$ & & $=\bar{n}$ & \\
\hline$=\underline{719}$ & & $=\frac{531}{2}$ & \\
\hline$=\overline{30}$ & & $=\overline{30}$ & \\
\hline$=23.9$ & & $=17.7$ & \\
\hline$S S_{1}=\sum x_{1}^{2}-\frac{\sum x_{1}^{2}}{n}$ & & $S S_{2}=\sum x_{2}^{2}-\frac{\sum x_{2}^{2}}{n}$ & \\
\hline$=17361-\frac{719^{2}}{30}$ & & $=9487-\frac{531^{2}}{30}$ & \\
\hline 516961 & & 281961 & \\
\hline$=1 / 361-\frac{30}{30}$ & & $=9487-\frac{30}{30}$ & \\
\hline$=17361-17232.0$ & & $=9487-9398.7$ & \\
\hline$S S_{1}=128.96$ & & $S S_{2}=88.3$ & \\
\hline$\sqrt{128.96}$ & & $\sqrt{88.3}$ & \\
\hline$S D_{1}=\frac{29}{29}$ & & $S D_{2}=\frac{29}{29}$ & \\
\hline$=\sqrt{4.447}$ & & $=\sqrt{3.0448}$ & \\
\hline$S D_{1}=2.10$ & & $S D_{2}=1.7449$ & \\
\hline
\end{tabular}

As

$t=\frac{x_{1}-x_{2}}{\sqrt{\left(\frac{S S_{1}+S S_{2}}{n_{1}+n_{2}-2}\right)\left(\frac{1}{n_{1}}+\frac{1}{n_{2}}\right)}}$

$t=\frac{719-531}{\sqrt{\left(\frac{128.96+88.3}{30+30-2}\right)\left(\frac{1}{30}+\frac{1}{30}\right)}}$

$t=\frac{188}{\sqrt{\left(\frac{217.26}{58}\right)\left(\frac{1}{15}\right)}}$

$t=\frac{188}{\sqrt{(3.745)(.0667)}}$

$t=\frac{188}{\sqrt{0.24}}$

$t=\frac{188}{0.499}$

$t=376.7$

As

$d f=n-1$

$d f=30-1$

$d f=29$

The value of

$d f=2.021$

$376>2.021$ 
So, $t>d f$ hence hypothesis is accepted

\begin{tabular}{|l|l|l|l|}
\hline & \multicolumn{1}{|l|}{ GCE } & SSC & T \\
\cline { 1 - 3 } M & 719 & 531 & \multirow{2}{*}{376.7} \\
\cline { 1 - 3 } SD & 2.10 & 1.74 & \\
\hline
\end{tabular}

As our $t=376.7$ value is greater than $d f$ value that is 2.021 so we reject null hypothesis and accept that there is a difference between the teaching methodologies used for GCE \& SSC levels.

\subsection{English Language Skill Observation Sheet For Students}

The second tool selected by the researchers was language skills observation sheet for students which was divided in the 4 components of language as listening, speaking, reading and writing. The researchers had observed both the education systems i.e. GCE and SSC for more than two months. 60 observations had been taken regularly on the basis of language skills. Each skill contains opinion based open questions which fulfills the desired outcomes of skills and is being judged on a scale as:

4 = Outstanding $3=$ Good $\quad 2=$ Fair $\quad 1=$ Poor

\subsection{Students' Behavior Deduced From Observation Sheet}

In the light of students' observation sheet, it has been deduced that there is an acute contrast between the students of GCE and SSC regarding to the English language skills i.e. listening, speaking, reading and writing. The competency level of GCE students is better than the SSC students.

\subsection{English Language Classroom Observation Sheet for Teachers}

The third tool selected by the researches was the English language classroom observation sheet for the teachers. It was divided in seven components of lesson planning as i.e. preparation, language use, language presentation, classroom management, classroom atmosphere, use of technology and use of teaching methodology. The researchers had observed both the education systems: GCE and SSC for more than two months. 60 observations had been taken regularly on the basis of lesson planning components. Each skill contains opinion based open questions which fulfilled the desired outcomes of skills and was judged on a scale as:

4=Outstanding 3= Good 2= Fair $\quad$ 1= Poor

\subsection{Teachers' Behavior Deduced From Observation Sheet}

From the teachers' observation sheet it has been observed that there is a clear contrast between the teaching methodologies of GCE and SSC teachers. The GCE classrooms are more effective in learning and the teaching methodology use by GCE teachers is advance and near to the natural approach toward language learning while the teaching methodologies used by SSC teachers more frequently i.e. the grammar translation method creates hindrance in language learning.

\section{FINDINGS}

The present study concludes that the institutional environment was found suitable for English language teaching in both the programs but it was found better at GCE (O-level) than the SSC level. The study also indicates that the mechanism of encouraging by the teachers was present in GCE O' level but it was not present in SSC level. The present study also concludes that the curriculum of O' Level develops creative and critical thinking but the SSC level curriculum was lacking in this area rather it promotes the culture of primary. It was also discovered that the content selected in the text books of both programs have a logical sequence and it was found that the content of $O^{\prime}$ level English language was internationally competitive and helpful in learning the second language.

This study also reveals from the results that there was no balanced focus on the four basic skills on the English language (i.e. listening, speaking, reading and writing). The SSC level course focuses on reading and writing skills whereas speaking and listening skill was entirely neglected at the SSC level.

Teaching methodology is a significant part of the instructional process. At $O$ ' level there is expository teaching (lectures) interactive learning, small group teaching / discussion, problem solving and individualization. There is an effective learning process, psychological factors, social and cultural factors, 
geographical setting at age range. $O$ ' level teaching emphasized on activities that require students to hypothize, analyze and make conclusions, generalization and teachers develops the creative thinking skills among the students. There is a balance between the teaching methodologies and student centered learning. But at SSC level, the teachers emphasize on reading and writing skills specific to the examination point of view for grade scoring. There is a lack of developing the basic learning skills among the students. This environment does not help the students to develop hypothesis, analyze, generalization, make conclusions and to promote creative thinking skill.

\section{CONCLUSIONS}

English language is taught as a compulsory subject in Pakistani institutions from class one to graduation level. The importance of English language has been emphasized since the creation of Pakistan in all the education policies right first education conference 1947 to the last national education policy 2010, the importance of English has been properly recognized.

Clear and well defined objectives set right directions for teaching-learning process. If objectives are not clear the whole process is blocked. If country has to survive honorably in international community its system of education must be well defined. In both the courses objective of English language were clear and well defined but at O-level these were relevant to the international demands.

The teaching methodologies at O-level are helpful in learning the four skills of language (i.e. reading, writing, listening, speaking). None of the area has been neglected by the teachers. It enhances the students' creative thinking but at SSC level teaching methodologies are promoting the cramming skills of students for the sake of getting high scores in examination. It does not fulfill all the requirements needed for the learning English as second language.

\section{SUGGESTIONS}

The success in teaching does not depend on the lesson program only and it is not confined with the teaching methodologies but more important is the way through which the teachers present their lessons and use various techniques to make their lessons more lively and enjoyable. The important factor is that the learning of students must be according to their needs. The researchers give some suggestions for the improvement of language learning as follow:

- Teacher should promote interactive techniques while teaching English.

- Teacher should lay emphasis on English as a medium of instruction in English classroom.

- The teacher should present the language in an enjoyable, relaxed and comprehensible way.

- Students should be encouraged and motivated to learn all the language skills equally.

- Some refresher courses should be arranged for better teaching of English language teachers.

\section{REFERENCE LIST}

Ashfaq, M. (1998). The study to evaluate the availability and utilization of teaching aids at secondary school level. (Unpublished) M.Ed. thesis, University of Arid Agriculture, Rawalpindi: pp. 68-69

Aslam, M. D. and A. Shair. (2004). Pakistan studies and its Teaching. Lahore: Every light press, p.138

Bahlol, G. (1998). A study to examine the difficulties of teachers in teaching English toclasses IX and $X$. (Unpublished) M.Ed. thesis, University Arid Agriculture, Rawalpindi: p.84

Bibi, A. (1995). Effect of English language games on the academic achievement of the secondary school students in N.W.F.P. Pakistan. (Unpublished) M. Phil thesis, Allama lqbal Open University, Islamabad. pp.118

Brookes, N. (1964). Language and Language Learning. New York: Harcourt, Brace and World, Inc., p.1

Chomsky, N. (1988). Language and Problems of Knowledge. London: Cambridge Mass MIT Press, p.39

DOV, L.A. (1986). Teacher sand Teacher Education in Developing Countries. London: Croom Helm Ltd, p.67 
IJAEDU- International E-Journal of Advances in Education, Vol. III, Issue 9, December 2017

Fincchiaro, M. and A.C. Brumfit. (1983). The Functional National Approach from Theory to Practice. London: Oxford University Press, pp. 7-91

French, F.G. (2000). Teaching English s international Language. London: Oxford University Press, p.12

Fries, L. (1998). English as global language and skills. London UK: Longmans Green and Co Ltd., pp. 67-78

Government of Pakistan. (1947). Proceedings of the All Pakistan Education Conference, Karachi: Education Division, Ministry of Interior. p.11

Government of Pakistan (1959). Report of the Commission on National Education.Karachi: Ministry of Education.

Government of Pakistan. (1979). National Education Policy and Implementation Programme of Government of Pakistan Ministry of Education Islamabad. Curriculum Development in Pakistan. 1986. Islamabad: AEPAM, pp. 3-17

Government of Pakistan. (1998). National Education Policy 1998-2010. Ministry of Education Islamabad. pp. 37-43, 55

Greancy, N. and P. Hasan. (1998). Public Examination in Pakistan. In: Perves Hoodbhoy (ed.), Education and the State: Fifty Years of Pakistan. Oxford University Press, Karachi. pp. 146-147

Haq, M.I. (1995). Developing Writing Skills in the Learning $9^{\text {th }}$ and $10^{\text {th }}$ Levels ofUrdu Medium. (Term Paper) M.A. TEFL, Allama Iqbal Open University, Islamabad. p.42

Harris, D.P. (1969). Testing English as second language. New. York: McGraw Hill Book Company, Inc, pp.9, 68-69

Henia, N.D. (2006). Teaching Forum 2006. USA Washington:Vol.44, p.5

Huckleberry, A.W. and E.S. Strother. (1966). Speech Education for the Elementary Teacher. Boston: Allyn and Bacan, Inc, p.20, 240

Ishtiaq, H (2005). An experimental study of Teaching English through Direct and Traditional Methods. P-18 (Unpublished ) PhD Thesis University of Arid Agriculture Rawalpindi Pakistan

James, A. (1982). Principles and Practice in Second Language Acquisition. New York: Pergamon Press. pp. 9-32

John. H and R Waseem, (1987). Grammar Course TEFL Code No. 552, Block 2, Allama lqbal Open University, Islamabad. p.65

Kayani, M. (2002). A comparative Study of Secondary and GCE O level Science Education Program in Pakistan. (Unpublished) Ph.D Thesis, University ofArid Agriculture Rawalpindi, Pakistan.

Khan, S.A. (2000). Evaluation of the Performance of Secondary School Teachers in the Subject of English in Rawalpindi Division. (Unpublished M.Phil thesis AridAgriculture University, Rawalpindi, Pakistan).

Lado, R. (2005). Language Teaching. New York:McGraw-Hill book Inc, pp. 174-175

Larson, F.D. (1986). Techniques and principles in Language Teaching. London: Oxford University Press, p. $18,86,123$

Malik F.J. (1996). The teaching of English in Pakistan, A Study in Teacher Education.

Lahore: Vanguard Book Pvt. Ltd. pp.12-14

Mansoor, S. (1993). Punjabi, Urdu, English in Pakistan. Lahore: Vanguard Book Pvt., Ltd., p. 8, 159

Maqsood, A. (2004). Teaching of Spelling to Secondary Students of Government Schools (Urdu Medium). (Unpublished) M.A TEFL Thesis Allama Iqbal Open University Islamabad Pakistan.

Moeen, A. (1992). English Language Teaching in Pakistan. Islamabad: National Book Foundation, p. 221

Naeem M. I. (2002). Problems of Teaching English in the Primary Schools ofSargodha Division and devising future strategies (un-published) M. PhilEducation Thesis Allama Iqbal Open University, Islamabad.

Naseem, N. (2007). Analysis of Errors made by students at matric level.(Unpublished) M.A TEFL Thesis Allama Iqbal Open University Islamabad Pakistan.

Naeemullah, M. (2007). Comparative study of curricula, teaching methodology and examination system of GCE (A-level) and F.Sc level in Basic Sciences.(Unpublished) Ph.D Thesis University of Arid 
Agricultural Rawalpindi Pakistan).

Nangia, S.B. (1993). Excellence of Teaching, a Model Approach. New Delhi: shish publishing, Punjabi Bagh, p.16

Nazir J. (2000). Teaching of English as a Second Language. Lahore Pakistan: The Caravans Book House Kactchery Bazar, pp.23-45, 56,67,78

Neilsen, K. (2003). Evaluation and Grading. Sydney. Australia: Aldine Publisher Company, p.64

Nunand, D. (2003). Practical English Language Teaching. Mc Graw Hill.

Rehman, T. (2003). Language Education and Culture. Oxford University Press. 2003 p.98, 89, 65

Richards, J. (1991). The Context of Language Teaching. London: Cambridge University Press, p.4,82

Richards, J. C. and S. Rodgers. (1986). Approaches and Methods in Language. Teaching. London: Cambridge University press, p.66

Rivers, W. M. (1981). Teaching Foreign Language Skills. Chicago, USA: University of Chicago Press, p.46

Safura, F. (2006). Motivation for Learning English Language at Secondary Level.(Unpublished) M.A TEFL Thesis Allama Iqbal Open University Islamabad Pakistan.

Scott, F.S., Bowley, C.S. Brocket, J.G. Brown and P.R. Doddered. (1978). English Grammar, A. Linguistic Study of its classes and structures. London: Longman Group Ltd. p. 21

Shams, B. (2003). The language Skills. Course Code 553 TEFL Publishing AIOU Islamabad Pakistan pp. 5460

Shirani, M. R. (1995). Utility of direct method for the development of language teaching. (Unpublished) M.A. TEFL, thesis, AIOU, Islamabad: p.24

Stockwell and Minkova D, (2001). English Words, UK :University Press UK.

Tang, J. (2002). Helping student develop coherence in writing. Teaching Forum 2002. USA Washington: Vol. 40, p. 41

The British Council. (1999). GCE Examination in Pakistan. The British Council Islamabad, pp. 1-7

The British Council. (2002). International Guide to Qualifications in Education. The British Council, Pakistan. p.59

Umbreen. (2008). A study on social acceptability of "O" and "A" level of education system and its implications in Pakistan. (Unpublished Ph.D Thesis University of Arid Agricultural Rawalpindi Pakistan).

Valdmain, A(ed) (2004). Studies in the second language acquisition. vol-26 No. 3 Cambridge University Press.

Waheed, A. (2005) .A Comparative Study of English Language writing courses meant for teaching writing skills at metric and $O$ levels. (Unpublished) M.A TEFL Thesis, Allama Iqbal Open University Islamabad Pakistan.

Wilkins, D.A. (1978). Linguistic on Language Teaching. London: Edward Arnold Publishers Ltd. p. 14, 67

Zehra, A. (1997). English language teaching at middle level in government schools of Punjab. (Unpublished) M.A. TEFL thesis, Allama Iqbal Open University, Islamabad. p.87 